\title{
Beitrag zum Nachweis des Glykokolls.
}

\author{
Von \\ Emil Abderhalden und Markus Guggenheim.
}

(Aus dem physiologischen Institut der tierärztlichen Hochschule, Berlin.)

(Der Redaktion zugegangen am 21. Januar 1909.)

Vor kurzem hat L. Hirschstein ${ }^{1}$ ) die Mitteilung gemacht, daß nach mehrtägigem Stehen einer Lösung von Glykokoll in $1-5 \%$ iger Kalilauge mit Hilfe von $\beta$-Naphthalinsulfochlorid kein Glykokoll mehr nachweisbar sei. Ja, es soll sogar eine ganz kurzdauernde Alkaliwirkung genügen, um das Glykokoll dem Nachweis zu entziehen. Es wurde z. B. eine frisch bereitete $1 \%$ ige Glykokollösung durch Zusatz von Kalilauge auf einen Gehalt von 5,00\%, 2,50\% und 1,25\% Alkali gebracht und dann sofort mit $\beta$-Naphthalinsulfochlorid geschüttelt. Hirschstein erhielt nur außerordentlich geringe Ausbeuten an $\beta$-Naphthalinsulfoglycin $(0,1016 \mathrm{~g}$ !). Diese Versuche beweisen nach Hirschstein mit aller Deutlichkeit, daß bei stärkerer Alkalikonzentration das Glykokoll entweder zerstört oder zum mindesten dem Nachweis mit $\beta$-Naphthalinsulfochlorid entzogen wird.

Diese Angaben von Hirschstein sind so auffallend, daß eine Nachprüfung durchaus erforderlich war, stehen doch eine ganze Anzahl von Beobachtungen in direktem Widerspruch mit seinen Befunden, ja der Nachweis von Aminosäuren mit Hilfe von $\beta$-Naphthalinsulfochlorid und anderen ähnlichen Verbindungen ist zum Teil in Frage gestellt.

Wir stellten zunächst fest, daß man ganz reines Glykokoll selbst mit 33\% igem Alkali kochen kann, ohne daß Ammoniak

1) L. Hirschstein, Weitere Ergebnisse über die Entstehung von Glykokoll aus Harnsäure. Archiv f. experim. Pathol. u. Pharmakologie, Bd. LIX, S. 401, 1908. 
entweicht. Auch bei längerem Stehen von Glykokoll in 1 bis $33 \%$ iger Lösung im Brutraume (1-8 Tage) ließ sich keine Entwicklung von Ammoniak nachweisen. Jedenfalls war nach dieser Richtung eine Veränderung des Glykokolls unter dem Einfluß von Alkali nicht nachzuweisen. $\mathrm{W}^{\top}$ ir haben dann weiterhin Glykokoll mit Alkali längere Zeit bei $37^{\circ}$ stehen gelassen, und es dann möglichst quantitativ wiedergewonnen. Wir isolierten es in einer Versuchsreihe als Esterchlorhydrat und in einer zweiten Versuchsreihe wählten wir, soweit es nach den kurzen Angaben von Hirschstein möglich war, genau die gleichen Versuchsbedingungen und die gleiche Isolierungsmethode, wie Hirschstein. Endlich haben wir das Glykokoll auch noch als Pikrat isoliert. Als Beleg seien die ersten beiden Versuchsreihen angeführt. Sie ergeben das eindeutige Resultat, daß das Glykokoll durch Einwirkung von 5\%igem Alkali sich dem Nachweis durch $\beta$-Naphthalinsulfochlorid nicht entzieht, und daß irgend eine Veränderung der genannten Aminosäure unter den von Hirschstein angegebenen Versuchsbedingungen nicht nachweisbar ist. Es ist uns. nicht verständlich, weshalb Hirschstein die Isolierung des Glykokolls mit Hilfe von $\beta$-Naphthalinsulfochlorid nicht gelang.

\section{Versuchsreihe.}

Folgende Lösungen wurden 9 Tage lang bei $37^{\circ}$ stehen gelassen:

I. $25 \mathrm{~g} \mathrm{KOH}, 5 \mathrm{~g}$ Glykokoll und $500 \mathrm{ccm}$ Wasser $=5 \% \mathrm{ige}$ KOH-Lösung und 1\%ige Glykokollösung.

II. $5 \mathrm{~g} \mathrm{KOH}$ und $5 \mathrm{~g}$ Glykokoll in $500 \mathrm{ccm}$ Wasser $=1 \% \mathrm{ige}$ Kali- und 1\%ige Glykokollösung.

III. $5 \mathrm{~g}$ Glykokoll und $5 \mathrm{~g} \mathrm{KOH}$ in $100 \mathrm{ccm}$ Wasser $=5 \%$ ige Glykokoll- und 5\% ige KOH-Lösung.

IV. $\check{\mathrm{g} g}$ Glykokoll, $5 \mathrm{~g} \mathrm{NaOH}$ und $500 \mathrm{ccm}$ Wasser $=1 \%$ ige Glykokoll- und 1\%ige Natriumhydroxydlösung.

Isoliert wurden statt der berechneten $9,3 \mathrm{~g}$ Glykollesterchlorhydrat:

I. 8,9 g, II. 9,05 g, III. 9,15 g, IV. 8,7 g. 


\section{Versuchsreihe.}

1. Eine Lösung von $5 \mathrm{~g}$ Glykokoll in $100 \mathrm{ccm} 5 \%$ iger KOH-Lösung wurde 5 Tage bei $37^{\circ}$ stehen gelassen, dann so viel Salzsäure zugegeben, daß die Lösung noch ein Äquivalent Alkali enthielt, und mit $30 \mathrm{~g} \beta$-Naphthalinsulfochlorid in ätherischer Lösung 5 Stunden lang geschüttelt. Während des Schüttelns wurden noch weitere 2 Äquivalente normaler Natriumhydroxydlösung zugefügt. Die ätherische Schicht wurde abgehoben und die wässerige Lösung mit Salzsäure angesäuert. Das $\beta$-Naphthalinsulfoglycin schied sich sofort als dichter krystallinischer, weißer Niederschlag ab. Die Ausbeute betrug $16 \mathrm{~g}$ (berechnet 17,66 g). F. vor dem Umkrystallisieren $153^{\circ}$. Das umkrystallisierte Produkt wog 15 g. F. $156^{\prime \prime}$ (korr.).

2. Aus einer analog behandelten Lösung von $2,5 \mathrm{~g}$ Glykokoll in $300 \mathrm{ccm} 1 \%$ iger $\mathrm{NaOH}$ ließen sich $8,8 \mathrm{~g}$ (berechnet $8,83 \mathrm{~g}$ ) isolieren. F. $153^{\circ}$. Das umkrystallisierte Produkt wog 8,0 g. F. $156^{\circ}$ (korr.).

Die aus beiden Versuchen gewonnenen Präparate zeigten alle Eigenschaften des $\beta$-Naphthalinsulfo-glycins. Die Analyse ergab $5,33 \%$ resp. $5,35 \% \mathrm{~N}$ (berechnet $5,28 \% \mathrm{~N}$ ). 